\title{
Exercise for Hypertension: A Prescription Update Integrating Existing Recommendations with Emerging Research
}

\author{
Linda S. Pescatello ${ }^{1}$ • Hayley V. MacDonald ${ }^{1}$ - Lauren Lamberti ${ }^{1}$ - Blair T. Johnson ${ }^{2}$
}

Published online: 30 September 2015

(C) The Author(s) 2015. This article is published with open access at Springerlink.com

\begin{abstract}
Hypertension is the most common, costly, and preventable cardiovascular disease risk factor. Numerous professional organizations and committees recommend exercise as initial lifestyle therapy to prevent, treat, and control hypertension. Yet, these recommendations differ in the components of the Frequency, Intensity, Time, and Type (FITT) principle of exercise prescription $\left(\operatorname{Ex} \bar{R}_{\mathrm{x}}\right)$; the evidence upon which they are based is only of fair methodological quality; and the individual studies upon which they are based generally do not include people with hypertension, which are some of the limitations in this literature. The purposes of this review are to (1) overview the professional exercise recommendations for hypertension in terms of the FITT principle of Ex $R_{x}$; (2) discuss new and emerging research related to $E x R_{x}$ for hypertension; and (3) present an updated FITT Ex $R_{x}$ for adults with hypertension that integrates the existing recommendations with this new and emerging research.
\end{abstract}

This article is part of the Topical Collection on Hypertension and the Brain

Linda S. Pescatello

Linda.Pescatello@uconn.edu

Hayley V. MacDonald

Hayley.MacDonald@uconn.edu

Lauren Lamberti

Lauren.Lamberti@uconn.edu

Blair T. Johnson

blair.t.johnson@chip.uconn.edu

1 Department of Kinesiology, College of Agriculture, Health, and Natural Resources, University of Connecticut, 2095 Hillside Rd, U-1110, Storrs, CT 06269-1110, USA

2 Department of Psychological Sciences, College of Liberal Arts and Sciences, University of Connecticut, 406 Babbidge Rd, U-1020, Storrs, CT 06269-1020, USA
Keywords Aerobic exercise $\cdot$ Blood pressure $\cdot$ Concurrent exercise · Postexercise hypotension · Prehypertension · Resistance exercise

\section{Introduction}

Hypertension is the most common, costly, and preventable cardiovascular disease (CVD) risk factor [1, 2]. Approximately 80 million Americans (33\%) have hypertension (systolic blood pressure $[\mathrm{SBP}] \geq 140 \mathrm{mmHg}$ and/or diastolic blood pressure $[\mathrm{DBP}] \geq 90 \mathrm{mmHg}$ ), and another 87 million (36\%) have prehypertension (SBP $\geq 120-<140 \mathrm{mmHg}$ and/or DBP $\geq 80-<90 \mathrm{mmHg}$ ); amounting to nearly $70 \%$ of Americans with high blood pressure (BP) [1]. Projections indicate that by 2030 over $40 \%$ of adults in the USA will acquire hypertension. From 2010 to 2030, the total direct costs attributed to hypertension are projected to triple from US\$130.7 to US $\$ 389.9$ billion, while the indirect costs due to lost productivity will almost double from US\$25.4 to US\$42.8 billion [2]. Lifestyle factors, such as participation in regular exercise, are recognized as key modifiable determinants of hypertension. Therefore, there is a need for more intensive efforts to promote these strategies to reduce the significant public health burden of hypertension [3].

Numerous randomized controlled trials (RCTs) have been conducted investigating the antihypertensive effects of exercise. In an attempt to better quantify the antihypertensive effects of exercise, many meta-analyses of these RCTs have been published $[4 \bullet \bullet, 5 \bullet \cdot$. These meta-analyses concluded that aerobic exercise training lowers blood pressure (BP) 5 $7 \mathrm{mmHg}$ [6-8], while dynamic resistance training lowers BP 2-3 mmHg [6, 8-11] among adults with hypertension. The magnitude of these BP reductions rivals the magnitude of those obtained with first-line antihypertensive medications 
[12] and lower CVD risk by 20-30 \% [13]. Exercising as little as 1 day per week is as effective (or even more so) than pharmacotherapy for reducing all-cause mortality among those with hypertension [14]. Furthermore, a recent network metaanalysis [15] of major exercise and drug trials showed no statistically detectable difference between exercise and drug interventions in mortality outcomes for coronary heart disease and prediabetes, and physical activity interventions were actually more effective for the secondary prevention of stroke mortality. For these reasons, the Joint National Commission (JNC) 7 [16], the JNC 8 [17] and American Heart Association (AHA)/American College of Cardiology 2013 Lifestyle Work Group [18], another recent AHA Scientific Statement [19], the American College of Sports Medicine (ACSM) [6], the European Society of Hypertension and European Society of Cardiology (ESH/ESC) [20], and the Canadian Hypertension Education Program (CHEP) [21] all recommend exercise for the prevention, treatment, and control of hypertension (Table 1).

Despite the general consensus that exercise, particularly aerobic exercise, lowers resting BP, our systematic reviews of 33 meta-analyses on the BP response to exercise [4••] and the existing professional exercise recommendations for hypertension $[5 \cdot \bullet$ revealed differences in the recommended components of the Frequency, Intensity, Time, and Type or FITT principle of exercise prescription $\left(\mathrm{Ex}_{\mathrm{x}}\right)$ as well as the reported magnitude of the BP reductions that result from them. Therefore, the purposes of this review are to (1) overview the existing professional exercise recommendations for hypertension in terms of the FITT principle of Ex $R_{x}$; (2) discuss new and emerging research related to the $E x R_{x}$ for hypertension; and (3) present an updated FITT Ex $\mathrm{R}_{\mathrm{x}}$ for adults with hypertension from our previous review [22] that integrates the existing recommendations with new and emerging research.

\section{Systematic Review Methods}

In this review, we have combined and updated the comprehensive search strategies used in our recently published systematic reviews $[4 \cdot \bullet, 5 \cdot \bullet]$ to include the potentially relevant literature on the BP response to the acute and chronic aerobic, dynamic resistance, and concurrent exercise since the publication of the ACSM position on exercise and hypertension [6]. The full search details for our systematic reviews have been published elsewhere $[4 \bullet \bullet]$. For our updated literature search, studies involving human adults ( $\geq 19$ years) that were published in English between January 1, 2004 and July 1, 2015, and had a control/comparison group were identified using the electronic database PubMed (including Medline). After omitting duplicates, our combined search yielded 5,412 potential reports, of which 560 were meta-analyses. Overall, 33 meta-analyses and 283 exercise trials were eligible for inclusion. Of those, the authors selected the most relevant meta-analyses $(l=7)$ and exercise studies $(n=63)$ for this review. Figure 1 details the search and selection process of the included meta-analyses and exercise trials.

\section{The Existing Professional Exercise Recommendations for Hypertension}

Prior to overviewing the professional exercise recommendations for hypertension, it is important to define what an Ex $R_{x}$ is as this definition will organize the discussion that follows. An Ex $R_{x}$ is the process whereby the recommended exercise regimen is designed in a systematic and individualized manner in terms of the Frequency (How Often?), Intensity (How Hard?), Time (How Long?), and Type (What Kind?), or the FITT principle of Ex $R_{x}[23 \cdot 0]$. As previously stated, exercise is recommended as a key lifestyle therapy among adults with hypertension by all professional committees and organizations listed in Table 1. We now overview the existing professional exercise recommendations for hypertension in terms of the FITT principle of Ex $R_{x}$ while commenting on new and emerging research.

\section{Frequency}

As Table 1 shows, all professional committees/organizations recommend exercising on most, if not all, days of the week with the exception of the Lifestyle Work Group [18] that recommended exercising 3-4 days per week for at least 12 weeks among adults with hypertension. Our group and others have shown that the reason exercise should be recommended on most, preferably all days, of the week is because BP is lower on the days people exercise compared to the days they do not exercise. This physiological response is termed postexercise hypotension $(\mathrm{PEH})[24,25]$. $\mathrm{PEH}$ is the immediate reduction in BP of 5-7 $\mathrm{mmHg}$ among people with hypertension that occurs after a single, isolated session of aerobic exercise of varying durations (10 to $50 \mathrm{~min}$ ) and intensities ( $40 \%$ up to $100 \%$ of maximum oxygen consumption $\left.\left[\mathrm{VO}_{2 \max }\right]\right)$, and these BP reductions are sustained for up to $24 \mathrm{~h}$ after the exercise bout $[6,26-42,43 \cdot \bullet]$.

The merits of PEH as antihypertensive lifestyle are further supported by two recent studies by Liu et al. [44] and Hecksteden et al. [45] who found that the BP response to acute exercise was strongly correlated with the more long-term BP response to exercise training. These findings support the long held notion that PEH may account for a significant amount of the magnitude of the BP reduction attributed to exercise training $[6,26,46]$. They also suggest that PEH could be used as a health screening tool to identify individuals with hypertension who respond to aerobic exercise as antihypertensive therapy. For individuals determined not to be responsive, alternative forms of treatment can then be more rapidly applied for the 


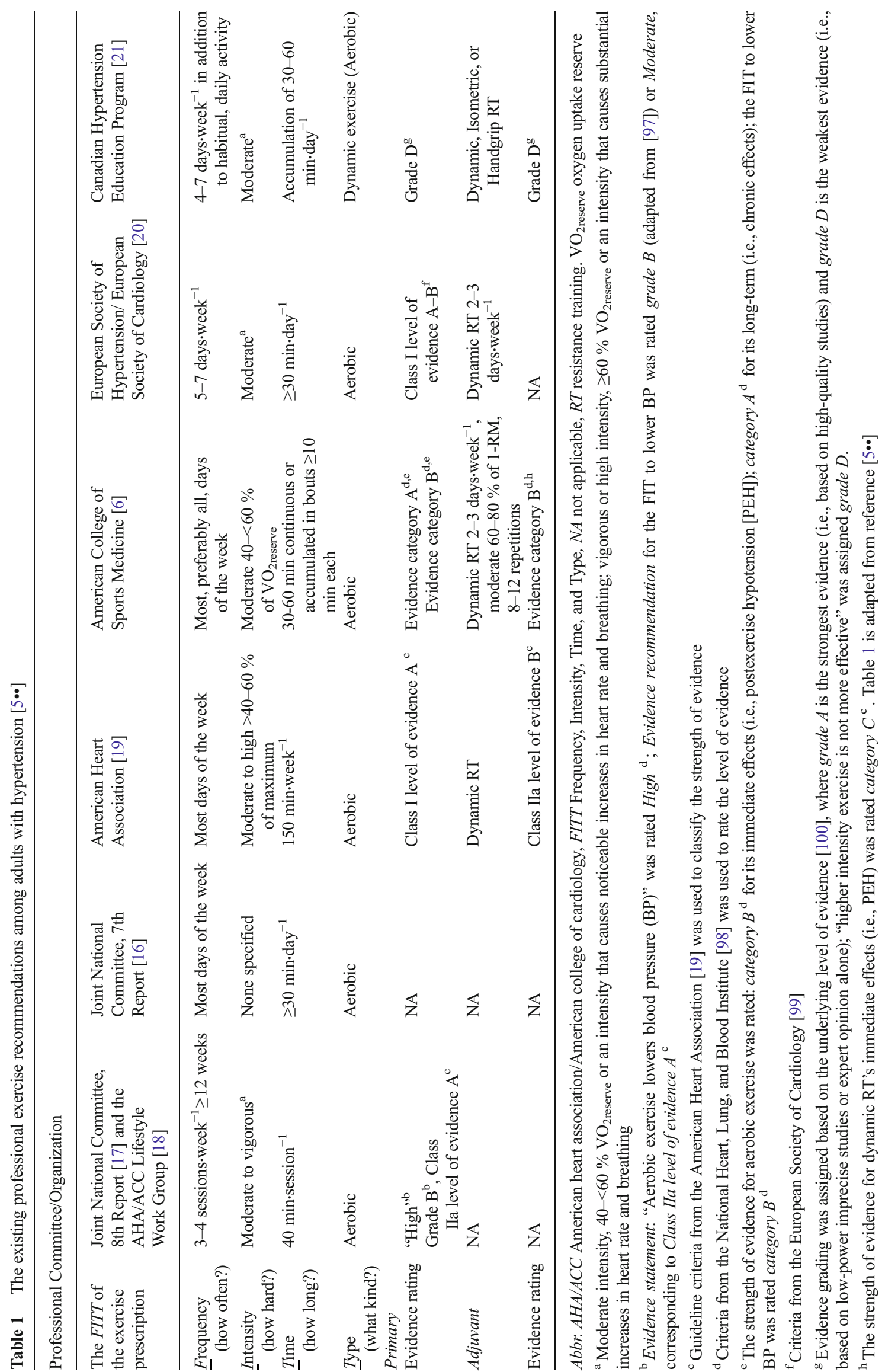


Fig. 1 Flow diagram detailing the systematic search for potentially relevant reports $(k)$ and the selection process of included meta-analyses $(l)$ and exercise trials (n). CINAHL cumulative index to nursing and allied health literature. EMBASEExcerpta Medica dataBASE. PEDro physiotherapy evidence database. $R C T s$ - Randomized controlled trials. RE-Resistance exercise. a Indicates the databases that were searched in our previous systematic review to locate relevant meta-analyses; the complete search strategy is available from reference $[4 \cdot \bullet] . ~ b$ Indicates the databases that were searched to locate potentially relevant exercise studies published since the ACSM position stand [6]; PubMed also includes the electronic database MEDLINE. Adapted from references $[4 \bullet \bullet, 5 \bullet \bullet, 43 \bullet \bullet]$

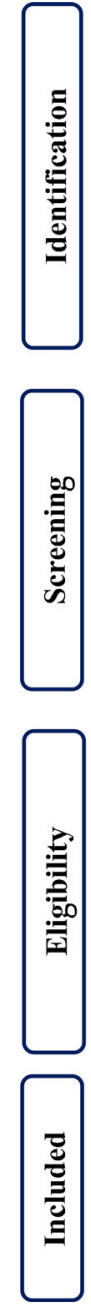

treatment and control of their high BP [47]. In fact, Luttrel and Halliwill's [48] conceptual model of recovery from exercise labeled PEH as a "window of opportunity" that can be exploited as a health screening tool to increase the effectiveness of exercise as antihypertensive lifestyle therapy.

Despite the clinical utility of PEH as antihypertensive therapy, only the ACSM [6] has addressed the merits of PEH by providing graded evidence for the antihypertensive effects of this seemingly important phenomenon. In addition to PEH, another reason for the recommendation of exercising on most, if not all, days of the week is that adults with hypertension are often overweight or obese, and a high frequency (days per week) or volume (metabolic energy equivalents $[\mathrm{MET}] \times$ minutes per week) of exercise is needed to achieve the caloric expenditure required for initial weight loss and successful maintenance of that weight loss [23••].

\section{Intensity}

The JNC 8 [17] and Lifestyle Work Group [18], AHA [19], ACSM [6], ESH/ESC [20], and CHEP [21] all recommend adults with hypertension engage in moderate intensity aerobic exercise ( $40 \%$ to $<60 \% \mathrm{VO}_{2 \max }$ or heart rate [HR] reserve), whereas the intensity of exercise was not specified by JNC 7 [16]. Of note, the Lifestyle Work Group [18] and AHA [19] also endorse vigorous intensity $\left(\geq 60 \% \mathrm{VO}_{2 \max }\right.$ or HR reserve) aerobic exercise for people with hypertension. This endorsement of vigorous intensity aerobic exercise incorporates new and emerging evidence from our laboratory, and others, showing that the magnitude of the BP reductions that result from acute and chronic aerobic exercise occur as a direct function of intensity such that the more rigorous the intensity, the greater the resultant BP reductions $[8,23 \bullet \bullet, 42,43 \cdot \bullet$, 49-58].

Eicher and colleagues [42] examined the antihypertensive effects of three bouts of acute aerobic exercise performed at light $\left(40 \% \mathrm{VO}_{2 \max }\right)$, moderate $\left(60 \% \mathrm{VO}_{2 \max }\right)$, and vigorous (a graded maximal exercise stress test to exhaustion or $100 \%$ $\mathrm{VO}_{2 \text { max }}$ ) intensity aerobic exercise among 45 middle aged, overweight men with pre- to stage 1 hypertension who were monitored in the laboratory and under ambulatory conditions. Eicher et al. [42] found that for each $10 \%$ increase in relative 
$\mathrm{VO}_{2 \max }$, SBP decreased $1.5 \mathrm{mmHg}\left(\mathrm{y}=-14.9 x+14.0, R^{2}=\right.$ $0.998)$ and DBP $0.6 \mathrm{mmHg}\left(\mathrm{y}=-5.9 x-0.3, R^{2}=0.969\right)$ over the course of the day time hours (Fig. 2). These findings suggest more vigorous levels of acute physical exertion lower BP to greater levels than lower levels of physical exertion among adults with hypertension who are willing and able to tolerate more intense levels of exercise.

High intensity interval training (HIIT) is defined as alternating periods of brief, very high intensity aerobic exercise $\left(>90 \% \mathrm{VO}_{2 \max }\right)$ separated by recovery periods of lower intensity exercise or rest [51]. Consistent with Eicher et al.'s findings [42], several investigators have found HIIT to be superior to continuous, moderate intensity aerobic exercise training for eliciting improvements in CVD risk factors when training programs were matched for exercise volume among a variety of populations, including adults with coronary artery disease, congestive heart failure, the metabolic syndrome, and overweight and obesity $[49,50,56,57]$. Furthermore, the magnitude of the BP reductions following HIIT was greater among samples with higher resting BP; $\sim 8 \mathrm{mmHg}$ for hypertension [49] and prehypertension [50] versus $\sim 3 \mathrm{mmHg}$ for normal BP [56]. These findings are consistent with the law of initial values that BP will be lowered to the greatest levels among those with higher resting BP [26]. Collectively, these new and emerging findings $[42,43 \bullet \bullet, 49,50,56,57]$ indicate that exercise intensity is an important determinant of the BP response to exercise such that increasing levels of physical exertion appear to lower BP in a dose-response pattern.

Holloway and colleagues recently examined the skeletal muscle [58] and cardiac [59] adaptations to 4 weeks of HIIT compared to traditional moderate intensity aerobic exercise training among Dahl salt-sensitive rats, an animal model of hypertension. They found HIIT had a negative impact on cardiac function and the overall oxidative capacity of skeletal muscle among the rats with hypertension, whereas moderate intensity aerobic exercise resulted in favorable cardiac and skeletal muscle adaptations. These provocative findings, in

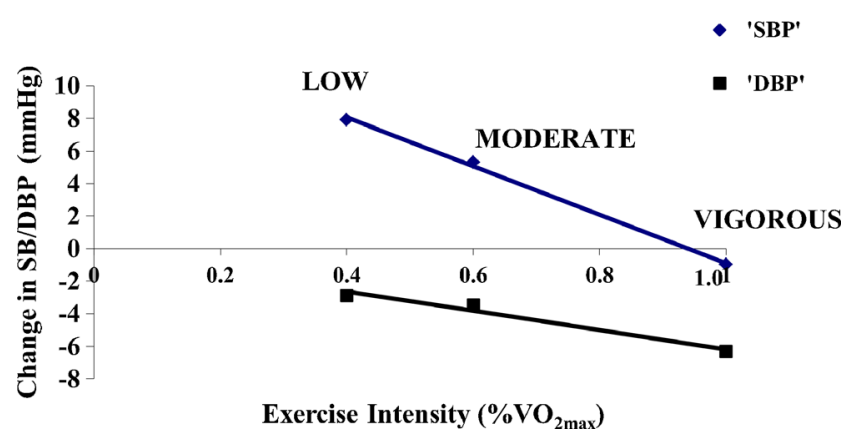

Fig. 2 Linear regression of the average blood pressure change from baseline following low, moderate, and vigorous intensity exercise. SBP systolic blood pressure. DBP diastolic blood pressure. $\mathrm{VO}_{2 \max }$ maximum oxygen consumption. Black diamond suit indicates SBP, $\mathrm{y}=-14.9 x+14.0$, $R^{2}=0.998$. Black square indicates DBP, $\mathrm{y}=-5.9 x-0.3, R^{2}=0.969(p s<$ 0.01). Adapted from reference [42] addition to the fact that adults with hypertension are predisposed to a transient increase in cardiovascular risk upon sudden vigorous exertion [60-62], highlight the need for further investigation to determine the benefit-to-risk ratio of exercising at vigorous intensity among adults with hypertension before the current recommendations in Table 1 can be expanded to include vigorous intensity exercise.

\section{Time}

All professional organizations and committees recommend exercising at least $30 \mathrm{~min}$ per day among people with hypertension. Consistent with the general consensus of most, preferably all, days of the week for the frequency recommendation, there is also a high level agreement among the professional organizations and committees in Table 1 that the duration of exercise should achieve a total of 150 or more minutes per week; an amount that is consistent with the recommendations for the general population [23••, 63, 64].

There is emerging evidence that acute aerobic exercise performed continuously in a single bout or accumulated in shorter bouts throughout the day can lower BP to similar levels and durations among adults with hypertension [43••, 55, 65-70]. Guidry et al. [71] compared the effects of a short $(15 \mathrm{~min})$ and long (30 $\mathrm{min})$ acute aerobic exercise bout performed at light $\left(40 \% \mathrm{VO}_{2 \max }\right)$ or moderate $\left(60 \% \mathrm{VO}_{2 \max }\right)$ intensity on PEH among 45 white, middle-aged overweight men with pre- to stage 1 hypertension. They found an acute bout of aerobic exercise performed for as short as $15 \mathrm{~min}$ at light to moderate intensity resulted in PEH for the remainder of the day [71]. In addition, Ciolac and co-investigators [72] randomized 52 men and women on antihypertensive medication to either $40 \mathrm{~min}$ of acute aerobic exercise performed continuously at $60 \% \mathrm{HR}$ reserve or an interval aerobic exercise session that alternated between $2 \mathrm{~min}$ at $50 \% \mathrm{HR}$ reserve and $1 \mathrm{~min}$ at $80 \% \mathrm{HR}$ reserve to total $40 \mathrm{~min}$. The continuous exercise group lowered ambulatory SBP and DBP 4-8 mmHg, while the interval exercise group lowered ambulatory SBP only 5-6 mmHg over $24 \mathrm{~h}$. Finally, Bhammar and colleagues [73] compared the effects of fractionized aerobic exercise (three 10-min bouts) interspersed throughout the day (morning, midday, and afternoon) and continuous aerobic exercise (one 30-min bout) performed at $60-65 \% \mathrm{VO}_{2 \max }$ on ambulatory $\mathrm{BP}$ among 11 young subjects with prehypertension. They found fractionized exercise was as at least as effective as continuous exercise in eliciting PEH until the following morning. Miyashita and colleagues [66] found that even shorter bouts of aerobic exercise (10 3-min bouts) interspersed throughout the day were as effective as a 30 -min bout of continuous aerobic exercise in eliciting PEH.

Collectively, these findings $[66,71-73]$ and others $[67-70$, 74] support that PEH is a low threshold phenomenon in terms of the duration of the exercise bout needed to produce the 
effect; and when these short bouts of exercise are interspersed throughout the day, $\mathrm{PEH}$ is a viable therapeutic lifestyle option for BP control among individuals with high BP. Not having the time to exercise is often a major deterrent to starting and maintaining a regular exercise program. For this reason, performing accumulated, shorter exercise bouts throughout the day (i.e., 3 to $10 \mathrm{~min}$ to total $30 \mathrm{~min}$ or more) would appear to be an attractive therapeutic option among adults with hypertension [43••, 65-74]. Nonetheless, future research is needed to determine if interspersing shorter bouts of aerobic exercise throughout the day may be used as a behavioral strategy to increase exercise adherence in this population.

\section{Type}

There is broad consensus supported by a strong rating of evidence that aerobic exercise should be prescribed as the primary type of exercise for the prevention, treatment, and control of hypertension. This recommendation is made by all professional organizations and committees in Table 1 because aerobic exercise training has been consistently shown to lower BP 5-7 mmHg among those with hypertension, levels that are twice that resulting from dynamic resistance training [6, 16-21]. The AHA [19], ACSM [6], ESH/ESC [20], and CHEP [21] recommend that adults with hypertension engage in dynamic resistance training as a supplement to aerobic exercise training, while the JNC 7 [16], JNC 8 [17], and Lifestyle Work Group [18] did not make any specific recommendations regarding dynamic resistance training.

As Table 1 shows, the level of evidence upon which the dynamic resistance training recommendations are made is weak, which may contribute to the lack of consensus among professional organizations and committees regarding the effectiveness of dynamic resistance training as antihypertensive therapy. One possible reason for this weak rating of evidence may be partially attributed to the dearth of primary level studies investigating dynamic resistance training as antihypertensive lifestyle therapy among adults with hypertension. This short-coming likely underestimates the effectiveness of dynamic resistance exercise training as antihypertensive lifestyle therapy due to the law of initial values, which predicts that the largest BP reductions would occur in adults with hypertension [5••, 6-8, 13, 26].

Indeed, several primary level studies have shown that the $\mathrm{BP}$ reductions following dynamic resistance training may be comparable in magnitude to those that result from aerobic exercise training among adults with high BP [43••, 75-84]. Mota and colleagues [84] found 16 weeks of moderate intensity dynamic resistance training reduced SBP/DBP about 14/ $4 \mathrm{mmHg}$ among 32 older women with controlled hypertension. Moraes et al. [85] found 12 weeks of moderate intensity dynamic resistance training reduced SBP/DBP approximately 16/12 $\mathrm{mmHg}$ among 15 middle-aged men with hypertension. In addition, several controlled trials [43••, 50, 76-78, 81,
86-88] directly comparing the effectiveness of aerobic exercise training versus dynamic resistance training as antihypertensive therapy found that SBP/DBP were reduced to similar levels among adults with untreated [76, 77] and controlled hypertension [78, 81], with no statistical difference between modalities. BP reductions of this magnitude following dynamic resistance training have also been reported among young [50, 86, 89] and middle-aged [87, 88, 90] adults with prehypertension. These findings suggest that moderate intensity dynamic resistance training may be viable as stand-alone antihypertensive lifestyle therapy among adults with hypertension. Nonetheless, more RCTs are needed to more definitively determine whether the existing professional exercise recommendations for hypertension should be expanded to include dynamic resistance training as stand-alone lifestyle therapy, and more precisely define for what patient populations and FIT features of dynamic resistance training programs would elicit the greatest BP benefits.

Last, it is not well understood how the combined effects of aerobic exercise and dynamic resistance training, termed concurrent exercise training, influence resting $\mathrm{BP}$ among adults with hypertension. Concurrent exercise training is defined as aerobic and dynamic resistance training performed in close proximity to each other (i.e., in a single session or on separate days) [43••, 91-93]. In light of evidence suggesting that dynamic resistance training may be as effective as aerobic exercise training as standalone antihypertensive lifestyle therapy among those with hypertension, the antihypertensive effects of concurrent exercise train-

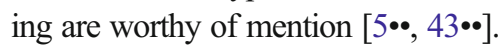

Hayashino et al. [94] performed a meta-analysis of 42 trials, of which 14 were concurrent exercise training trials. Overall, the sample included middle-aged adults with type 2 diabetes mellitus and about $36 \%$ had hypertension. The authors [94] reported SBP/DBP reductions following aerobic exercise training of 1.7/2.3 $\mathrm{mmHg}$, dynamic resistance training of 2.8/ $2.3 \mathrm{mmHg}$, and concurrent exercise training of $3.2 / 1.9 \mathrm{mmHg}$, $\mathrm{BP}$ reductions that were not different among the three modalities of exercise. Furthermore, Cornelissen and Smart [8] found in a sample of 93 trials, of which 14 included concurrent exercise training trials, BP was reduced 3.5/2.5 $\mathrm{mmHg}$ following aerobic exercise training, $1.8 / 3.2 \mathrm{mmHg}$ following dynamic resistance training, and $2.2 \mathrm{mmHg}$ (SBP only) following concurrent exercise training, and once again, the BP reductions were not different among the three modality groups. Clearly, further investigation is needed to explore the promising merits of concurrent exercise training as antihypertensive lifestyle therapy.

\section{An Exercise Prescription for Hypertension Update}

The FITT Ex $\mathrm{R}_{\mathrm{x}}$ recommendations that follow are based upon the existing exercise recommendations for hypertension 
displayed in Table 1, while integrating the new and emerging research we have discussed in this review.

\section{Frequency}

Aerobic exercise on most, preferably all days of the week and dynamic resistance exercise on 2 to 3 days in that same week.

\section{Intensity}

Moderate intensity aerobic exercise (i.e., 40 to $<60 \% \mathrm{VO}_{2 \max }$ or HR reserve; 11-13 rating of perceived exertion [RPE] on the 620 Borg Scale $[95,96])$ and moderate intensity dynamic resistance exercise (60\% to $80 \%$ one repetition maximum [1-RM]).

Due to emerging evidence that the BP reductions resulting from exercise are dose-dependent upon the intensity of exercise [42, 43••, 49-52, 56, 57, 72], the intensity recommendation may be expanded in the future to include vigorous intensity pending the results of future research that better establishes the benefits and risks of more rigorous levels of exercise among those with hypertension.

\section{Time}

Aerobic exercise should be performed for 30 to $60 \mathrm{~min}$ per day that is continuous or accumulated. If accumulated, bouts should be at least $10 \mathrm{~min}$ in duration to total 30 to $60 \mathrm{~min}$ of exercise per day. Dynamic resistance exercise should consist of two to three sets of 10 to 12 repetitions for 8 to 10 exercises that target the major muscle groups of the upper and lower body. The duration of exercise should total $150 \mathrm{~min}$ or more per week.

\section{Type}

Examples of aerobic activities may include walking, jogging, cycling, and swimming. Dynamic resistance training equipment may include machine weights, free weights, and resistance bands, as well as functional body weight exercises.

Due to evidence supporting the merits of both dynamic resistance [75-84] and concurrent exercise training [8, 43••, 94], it seems prudent that adults with hypertension should perform combinations of aerobic and dynamic resistance exercise during a given week. However, due to the weak and limited nature of this literature (Table 1) $[4 \bullet \bullet, 5 \bullet \cdot$, further research is needed to explore the merits of dynamic resistance and concurrent exercise training as antihypertensive therapy.

\section{Progression}

The FITT principle of Ex $R_{x}$ relating to progression for healthy adults generally applies to those with hypertension [63]. Progression should be gradual, avoiding large increases in any of the FITT components of the Ex $R_{x}$, especially intensity $[23 \cdot \bullet]$. Health care and exercise professionals should also consider the level of BP control, recent changes in antihypertensive drug therapy, medication-related adverse and exercise effects, and the presence of target organ disease and/or other comorbidities with adjustments made accordingly $[5 \bullet \cdot, 6$, $23 \bullet \bullet$.

\section{Conclusion}

Hypertension is arguably one of the most important CVD risk factors due to its high prevalence and medical costs [1]. Indeed, nearly $70 \%$ of Americans have preto established hypertension. Aerobic exercise is universally recommended as initial lifestyle therapy for individuals with hypertension because it lowers BP 5$7 \mathrm{mmHg}$ among adults with hypertension. Nonetheless, the components of the FITT principle of Ex $R_{x}$ differ among the existent recommendations [5••]. Considering both the exercise recommendations for hypertension in Table 1 and new and emerging literature, we have formulated an updated FITT Ex $\mathrm{R}_{\mathrm{x}}$ from our previous review [22] as follows: a combination of $30 \mathrm{~min}$ or more per day of moderate intensity aerobic exercise on most, preferably all, days of the week and dynamic resistance exercise 2 to 3 days per week to total $150 \mathrm{~min}$ or more of exercise per week. The notable difference in this updated FITT Ex $R_{x}$ from our previous review is a greater emphasis on inclusion of dynamic resistance exercise in combination with aerobic exercise. Further investigation is needed to more precisely establish the FIT combinations of aerobic and resistance exercise that elicit the greatest BP benefit among adults with hypertension.

\section{Compliance with Ethics Guidelines}

Conflict of Interest Dr. Pescatello, Dr. MacDonald, and Ms. Lamberti declare that they have no conflicts of interest. Dr. Johnson declares personal fees from the American College of Sports Medicine.

Human and Animal Rights and Informed Consent This article does not contain any studies with human or animal subjects performed by any of the authors.

Open Access This article is distributed under the terms of the Creative Commons Attribution 4.0 International License (http:// creativecommons.org/licenses/by/4.0/), which permits unrestricted use, distribution, and reproduction in any medium, provided you give appropriate credit to the original author(s) and the source, provide a link to the Creative Commons license, and indicate if changes were made. 


\section{References}

Papers of particular interest, published recently, have been highlighted as:

•- Of major importance

1. Mozaffarian D, Benjamin EJ, Go AS, Arnett DK, Blaha MJ, Cushman M, et al. Heart disease and stroke statistics-2015 update: a report from the American Heart Association. Circulation. 2015;131:e29-e322.

2. Heidenreich PA, Trogdon JG, Khavjou OA, Butler J, Dracup K, Ezekowitz MD, et al. Forecasting the future of cardiovascular disease in the United States: a policy statement from the American Heart Association. Circulation. 2011;123:933-44.

3. Egan BM, Li J, Hutchison FN, Ferdinand KC. Hypertension in the United States, 1999 to 2012: Progress toward Healthy People 2020 goals. Circulation. 2014;130:1692-9.

4.• Johnson BT, MacDonald HV, Bruneau Jr ML, Goldsby TU, Brown JC, Huedo-Medina TB, et al. Methodological quality of meta-analyses on the blood pressure response to exercise: a review. J Hypertens. 2014;32:706-23. This systematic review of meta-analyses on the blood pressure response to exercise details the search strategy used for this review as well as provides an extensive discussion of the state of the exercise and hypertension literature.

5.• Pescatello LS, MacDonald HV, Ash GI, Lambert LM, Farquhar $\mathrm{WB}$, Arena R, et al. Assessing the existing professional exercise recommendations for hypertension: a review and recommendations for future research priorities. Mayo Clin Proc. 2015;90: 801-12. This systematic review elaborates on the existing professional recommendations for exercise and hypertension and contains a detailed discussion of why the recommendations differ and directions for future research.

6. Pescatello LS, Franklin BA, Fagard R, Farquhar WB, Kelley GA, Ray CA, et al. American college of sports medicine position stand: exercise and hypertension. Med Sci Sports Exerc. 2004;36:53353.

7. Cornelissen VA, Fagard RH. Effects of endurance training on blood pressure, blood pressure-regulating mechanisms, and cardiovascular risk factors. Hypertension. 2005;46:667-75.

8. Cornelissen VA, Smart NA. Exercise training for blood pressure: a systematic review and meta-analysis. J Am Heart Assoc. 2013;2, e004473.

9. Kelley GA, Kelley KS. Progressive resistance exercise and resting blood pressure: a meta-analysis of randomized controlled trials. Hypertension. 2000;35:838-43.

10. Cornelissen VA, Fagard RH. Effect of resistance training on resting blood pressure: a meta-analysis of randomized controlled trials. J Hypertens. 2005;23:251-9.

11. Cornelissen VA, Fagard RH, Coeckelberghs E, Vanhees L. Impact of resistance training on blood pressure and other cardiovascular risk factors: a meta-analysis of randomized, controlled trials. Hypertension. 2011;58:950-8

12. ALLHAT Officers and Coordinators for the ALLHAT Collaborative Research Group. Major outcomes in high-risk hypertensive patients randomized to angiotensin-converting enzyme inhibitor or calcium channel blocker vs diuretic: The Antihypertensive and LipidLowering Treatment to Prevent Heart Attack Trial (ALLHAT). JAMA. 2002;288:2981-97.

13. Whelton SP, Chin A, Xin X, He J. Effect of aerobic exercise on blood pressure: a meta-analysis of randomized, controlled trials. Ann Intern Med. 2002;136:493-503.

14. Brown RE, Riddell MC, Macpherson AK, Canning KL, Kuk JL. The joint association of physical activity, blood-pressure control, and pharmacologic treatment of hypertension for all-cause mortality risk. Am J Hypertens. 2013;26:1005-10.

15. Naci H, Ioannidis JP. Comparative effectiveness of exercise and drug interventions on mortality outcomes: Metaepidemiological study. BMJ. 2013;347:f5577.

16. Chobanian AV, Bakris GL, Black HR, Cushman WC, Green LA, Izzo Jr JL, et al. Seventh report of the joint national committee on prevention, detection, evaluation, and treatment of high blood pressure. Hypertension. 2003;42:1206-52.

17. James PA, Oparil S, Carter BL, Cushman WC, DennisonHimmelfarb C, Handler J, et al. Evidence-based guideline for the management of high blood pressure in adults: Report from the panel members appointed to the eighth Joint National Committee (JNC 8). JAMA. 2014;311:507-20. doi:10.1001/ jama.2013.284427; 10.1001/jama.2013.284427.

18. Eckel RH, Jakicic JM, Ard JD, de Jesus JM, Houston Miller N, Hubbard VS, et al. 2013 AHA/ACC guideline on lifestyle management to reduce cardiovascular risk: a report of the American College of Cardiology/American Heart Association task force on practice guidelines. J Am Coll Cardiol. 2014;63:2960-84.

19. Brook RD, Appel LJ, Rubenfire M, Ogedegbe G, Bisognano JD, Elliott WJ, et al. Beyond medications and diet: alternative approaches to lowering blood pressure: a scientific statement from the American heart association. Hypertension. 2013;61:1360-83.

20. Mancia G, Fagard R, Narkiewicz K, Redon J, Zanchetti A, Bohm $\mathrm{M}$, et al. $2013 \mathrm{ESH} / \mathrm{ESC}$ practice guidelines for the management of arterial hypertension. Blood Press. 2014;23:3-16.

21. Dasgupta K, Quinn RR, Zarnke KB, Rabi DM, Ravani P, Daskalopoulou SS, et al. The 2014 Canadian hypertension education program recommendations for blood pressure measurement, diagnosis, assessment of risk, prevention, and treatment of hypertension. Can J Cardiol. 2014;30:485-501.

22. Pescatello LS. Exercise and hypertension: recent advances in exercise prescription. Curr Hypertens Rep. 2005;7:281-6.

23.• Pescatello LS, Arena R, Riebe D, Thompson PD. ACSM's guidelines for exercise testing and prescription. 9th ed. Baltimore: Lippincott Williams and Wilkins; 2013. The ACSM Guidelines for Exercise Testing and Prescription are the gold standard for anyone conducting exercise testing and programs. They contain detailed information on the FITT principle of Ex Rx among healthy populations, adults with hypertension, and other chronic diseases and health conditions that often coexist with hypertension including overweight and obesity, the metabolic syndrome, and dyslipidemia, among others.

24. Fitzgerald W. Labile hypertension and jogging: New diagnostic tool or spurious discovery? Br Med J (Clin Res Ed). 1981;282: $542-4$.

25. Kenney MJ, Seals DR. Postexercise hypotension. Key features, mechanisms, and clinical significance. Hypertension. 1993;22: 653-64.

26. Pescatello LS, Kulikowich JM. The aftereffects of dynamic exercise on ambulatory blood pressure. Med Sci Sports Exerc. 2001;33:1855-61.

27. Quinn TJ. Twenty-four hour, ambulatory blood pressure responses following acute exercise: Impact of exercise intensity. J Hum Hypertens. 2000;14:547-53.

28. Kraul J, Chrastek J, Adamirova J. The hypotensive effect of physical activity. In: Rabb W, editor. Prevention of ischemic heart disease: principles and practice. Springfield, IL: Charles C Thomas; 1966.

29. Bennett T, Wilcox RG, Macdonald IA. Post-exercise reduction of blood pressure in hypertensive men is not due to acute impairment of baroreflex function. Clin Sci (Lond). 1984;67:97-103.

30. Brandao Rondon MU, Alves MJ, Braga AM, Teixeira OT, Barretto AC, Krieger EM, et al. Postexercise blood pressure 
reduction in elderly hypertensive patients. J Am Coll Cardiol. 2002;39:676-82.

31. Cleroux J, Kouame N, Nadeau A, Coulombe D, Lacourciere Y. Aftereffects of exercise on regional and systemic hemodynamics in hypertension. Hypertension. 1992;19:183-91.

32. Floras JS, Hara K. Sympathoneural and haemodynamic characteristics of young subjects with mild essential hypertension. J Hypertens. 1993;11:647-55.

33. Floras JS, Sinkey CA, Aylward PE, Seals DR, Thoren PN, Mark AL. Postexercise hypotension and sympathoinhibition in borderline hypertensive men. Hypertension. 1989;14:28-35.

34. Wilcox RG, Bennett T, Brown AM, Macdonald IA. Is exercise good for high blood pressure? Br Med J (Clin Res Ed). 1982;285:767-9.

35. Pescatello LS, Guidry MA, Blanchard BE, Kerr A, Taylor AL, Johnson AN, et al. Exercise intensity alters postexercise hypotension. J Hypertens. 2004;22:1881-8.

36. Pescatello LS, Fargo AE, Leach Jr CN, Scherzer HH. Short-term effect of dynamic exercise on arterial blood pressure. Circulation. 1991;83:1557-61.

37. Wallace JP, Bogle PG, King BA, Krasnoff JB, Jastremski CA. The magnitude and duration of ambulatory blood pressure reduction following acute exercise. J Hum Hypertens. 1999;13:361-6.

38. Paulev PE, Jordal R, Kristensen O, Ladefoged J. Therapeutic effect of exercise on hypertension. Eur J Appl Physiol Occup Physiol. 1984;53:180-5.

39. MacDonald JR, Hogben CD, Tarnopolsky MA, MacDougall JD. Post exercise hypotension is sustained during subsequent bouts of mild exercise and simulated activities of daily living. J Hum Hypertens. 2001;15:567-71.

40. Hagberg JM, Montain SJ, Martin WH. Blood pressure and hemodynamic responses after exercise in older hypertensives. J Appl Physiol. 1987;63:270-6.

41. Taylor-Tolbert NS, Dengel DR, Brown MD, McCole SD, Pratley RE, Ferrell RE, et al. Ambulatory blood pressure after acute exercise in older men with essential hypertension. Am J Hypertens. 2000;13:44-51.

42. Eicher JD, Maresh CM, Tsongalis GJ, Thompson PD, Pescatello LS. The additive blood pressure lowering effects of exercise intensity on post-exercise hypotension. Am Heart J. 2010;160:51320.

43.• Pescatello LS. Effects of exercise on hypertension: From cells to physiological systems. In: Coleman WB, Tsongalis GJ, editors. Molecular and translational medicine. Switzerland: Springer International Publishing; 2015. p. pp. 3-86. This book is the first primer on the effects of exercise on human hypertension that describes the state-of-the-art effects of exercise on the many factors underlying essential hypertension in humans. Distinguished experts present current research on the effects of exercise on the physiological systems involved in blood pressure regulation and the effects of aerobic, resistance, and concurrent exercise on the blood pressure response to exercise.

44. Liu S, Goodman J, Nolan R, Lacombe S, Thomas SG. Blood pressure responses to acute and chronic exercise are related in prehypertension. Med Sci Sports Exerc. 2012;44:1644-52.

45. Hecksteden A, Grutters T, Meyer T. Association between postexercise hypotension and long-term training-induced blood pressure reduction: a pilot study. Clin J Sport Med. 2013;23:58-63.

46. Haskell WL, Wolffe JB. Memorial lecture. Health consequences of physical activity: understanding and challenges regarding doseresponse. Med Sci Sports Exerc. 1994;26:649-60.

47. Bouchard C, Blair SN, Church TS, Earnest CP, Hagberg JM, Hakkinen $\mathrm{K}$, et al. Adverse metabolic response to regular exercise: Is it a rare or common occurrence? PLoS One. 2012;7, e37887.

48. Luttrell MJ, Halliwill JR. Recovery from exercise: Vulnerable state, window of opportunity, or crystal ball? Front Physiol. 2015;6:204.
49. Molmen-Hansen HE, Stolen T, Tjonna AE, Aamot IL, Ekeberg IS, Tyldum GA, et al. Aerobic interval training reduces blood pressure and improves myocardial function in hypertensive patients. Eur J Prev Cardiol. 2012;19:151-60.

50. Beck DT, Martin JS, Casey DP, Braith RW. Exercise training improves endothelial function in resistance arteries of young prehypertensives. J Hum Hypertens. 2014;28:303-9.

51. Kessler HS, Sisson SB, Short KR. The potential for high-intensity interval training to reduce cardiometabolic disease risk. Sports Med. 2012;42:489-509.

52. Swain DP, Franklin BA. Comparison of cardioprotective benefits of vigorous versus moderate intensity aerobic exercise. Am J Cardiol. 2006;97:141-7.

53. Tjonna AE, Lee SJ, Rognmo O, Stolen TO, Bye A, Haram PM, et al. Aerobic interval training versus continuous moderate exercise as a treatment for the metabolic syndrome: a pilot study. Circulation. 2008;118:346-54.

54. Weston KS, Wisloff U, Coombes JS. High-intensity interval training in patients with lifestyle-induced cardiometabolic disease: a systematic review and meta-analysis. Br J Sports Med. 2014;48: 1227-34.

55. Ciolac EG. High-intensity interval training and hypertension: Maximizing the benefits of exercise? Am J Cardiovasc Dis. 2012;2:102-10.

56. Heydari M, Boutcher YN, Boutcher SH. High-intensity intermittent exercise and cardiovascular and autonomic function. Clin Auton Res. 2013;23:57-65.

57. Gibala MJ, Little JP, Macdonald MJ, Hawley JA. Physiological adaptations to low-volume, high-intensity interval training in health and disease. J Physiol. 2012;590:1077-84.

58. Holloway TM, Bloemberg D, da Silva ML, Quadrilatero J, Spriet LL. High-intensity interval and endurance training are associated with divergent skeletal muscle adaptations in a rodent model of hypertension. Am J Physiol Regul Integr Comp Physiol. 2015;308:R927-34.

59. Holloway TM, Bloemberg D, da Silva ML, Simpson JA, Quadrilatero J, Spriet LL. High intensity interval and endurance training have opposing effects on markers of heart failure and cardiac remodeling in hypertensive rats. PLoS One. 2015;10, e0121138.

60. Thompson PD, Franklin BA, Balady GJ, Blair SN, Corrado D, Estes 3rd NA, et al. Exercise and acute cardiovascular events placing the risks into perspective: a scientific statement from the american heart association council on nutrition, physical activity, and metabolism and the council on clinical cardiology. Circulation. 2007;115:2358-68.

61. Rognmo O, Moholdt T, Bakken H, Hole T, Molstad P, Myhr NE, et al. Cardiovascular risk of high- versus moderate-intensity aerobic exercise in coronary heart disease patients. Circulation. 2012;126:1436-40.

62. Siscovick DS, Weiss NS, Fletcher RH, Lasky T. The incidence of primary cardiac arrest during vigorous exercise. N Engl J Med. 1984;311:874-7.

63. Garber CE, Blissmer B, Deschenes MR, Franklin BA, Lamonte MJ, Lee IM, et al. American college of sports medicine position stand. Quantity and quality of exercise for developing and maintaining cardiorespiratory, musculoskeletal, and neuromotor fitness in apparently healthy adults: guidance for prescribing exercise. Med Sci Sports Exerc. 2011;43:1334-59.

64. Office of Disease Prevention and Health Promotion. 2008 physical activity guidelines for Americans. US Department of Health and Human Services. 2008. http://www.health.gov/paguidelines

65. Jones H, Taylor CE, Lewis NC, George K, Atkinson G. Postexercise blood pressure reduction is greater following intermittent than continuous exercise and is influenced less by diurnal variation. Chronobiol Int. 2009;26:293-306. 
66. Miyashita M, Burns SF, Stensel DJ. Accumulating short bouts of running reduces resting blood pressure in young normotensive/ pre-hypertensive men. J Sports Sci. 2011;29:1473-82.

67. Lacombe SP, Goodman JM, Spragg CM, Liu S, Thomas SG. Interval and continuous exercise elicit equivalent postexercise hypotension in prehypertensive men, despite differences in regulation. Appl Physiol Nutr Metab. 2011;36:881-91.

68. Padilla J, Wallace JP, Park S. Accumulation of physical activity reduces blood pressure in pre- and hypertension. Med Sci Sports Exerc. 2005;37:1264-75.

69. Park S, Rink LD, Wallace JP. Accumulation of physical activity: blood pressure reduction between 10-min walking sessions. J Hum Hypertens. 2008;22:475-82.

70. Park S, Rink LD, Wallace JP. Accumulation of physical activity leads to a greater blood pressure reduction than a single continuous session, in prehypertension. J Hypertens. 2006;24:1761-70.

71. Guidry MA, Blanchard BE, Thompson PD, Maresh CM, Seip RL, Taylor AL, et al. The influence of short and long duration on the blood pressure response to an acute bout of dynamic exercise. Am Heart J. 2006;151:1322-e5,1322.12.

72. Ciolac EG, Guimaraes GV, D Avila VM, Bortolotto LA, Doria EL, Bocchi EA. Acute effects of continuous and interval aerobic exercise on 24-h ambulatory blood pressure in long-term treated hypertensive patients. Int J Cardiol. 2009;133:381-7.

73. Bhammar DM, Angadi SS, Gaesser GA. Effects of fractionized and continuous exercise on 24-h ambulatory blood pressure. Med Sci Sports Exerc. 2012;44:2270-6.

74. Angadi SS, Weltman A, Watson-Winfield D, Weltman J, Frick K, Patrie J, et al. Effect of fractionized vs continuous, single-session exercise on blood pressure in adults. J Hum Hypertens. 2010;24: $300-2$.

75. Harris KA, Holly RG. Physiological response to circuit weight training in borderline hypertensive subjects. Med Sci Sports Exerc. 1987;19:246-52.

76. Norris R, Carroll D, Cochrane R. The effects of aerobic and anaerobic training on fitness, blood pressure, and psychological stress and well-being. J Psychosom Res. 1990;34:367-75.

77. Blumenthal JA, Siegel WC, Appelbaum M. Failure of exercise to reduce blood pressure in patients with mild hypertension. Results of a randomized controlled trial. JAMA. 1991;266:2098-104.

78. Castaneda C, Layne JE, Munoz-Orians L, Gordon PL, Walsmith J, Foldvari $\mathrm{M}$, et al. A randomized controlled trial of resistance exercise training to improve glycemic control in older adults with type 2 diabetes. Diabetes Care. 2002;25:2335-41.

79. Thomas GN, Hong AW, Tomlinson B, Lau E, Lam CW, Sanderson $\mathrm{JE}$, et al. Effects of tai chi and resistance training on cardiovascular risk factors in elderly Chinese subjects: a 12-month longitudinal, randomized, controlled intervention study. Clin Endocrinol (Oxf). 2005;63:663-9.

80. Terra DF, Mota MR, Rabelo HT, Bezerra LM, Lima RM, Ribeiro $\mathrm{AG}$, et al. Reduction of arterial pressure and double product at rest after resistance exercise training in elderly hypertensive women. Arq Bras Cardiol. 2008;91:299-305.

81. Jorge ML, de Oliveira VN, Resende NM, Paraiso LF, Calixto A, Diniz AL, et al. The effects of aerobic, resistance, and combined exercise on metabolic control, inflammatory markers, adipocytokines, and muscle insulin signaling in patients with type 2 diabetes mellitus. Metabolism. 2011;60:1244-52.

82. Park YH, Song M, Cho BL, Lim JY, Song W, Kim SH. The effects of an integrated health education and exercise program in community-dwelling older adults with hypertension: a randomized controlled trial. Patient Educ Couns. 2011;82:133-7.
83. Oliveira VN, Bessa A, Jorge MLMP, Oliveira RJS, de Mello MT, De Agostini GG, et al. The effect of different training programs on antioxidant status, oxidative stress, and metabolic control in type 2 diabetes. Appl Physiol Nutr Metab. 2012;37:334-44.

84. Mota MR, Oliveira RJ, Terra DF, Pardono E, Dutra MT, de Almeida JA, et al. Acute and chronic effects of resistance exercise on blood pressure in elderly women and the possible influence of ACE I/D polymorphism. Int J Gen Med. 2013;6:581-7.

85. Moraes MR, Bacurau RF, Casarini DE, Jara ZP, Ronchi FA, Almeida SS, et al. Chronic conventional resistance exercise reduces blood pressure in stage 1 hypertensive men. J Strength Cond Res. 2012;26:1122-9.

86. Croymans DM, Krell SL, Oh CS, Katiraie M, Lam CY, Harris RA, et al. Effects of resistance training on central blood pressure in obese young men. J Hum Hypertens. 2014;28:157-64.

87. Sarsan A, Ardic F, Ozgen M, Topuz O, Sermez Y. The effects of aerobic and resistance exercises in obese women. Clin Rehabil. 2006;20:773-82.

88. Sillanpaa E, Hakkinen A, Punnonen K, Hakkinen K, Laaksonen DE. Effects of strength and endurance training on metabolic risk factors in healthy 40-65-year-old men. Scand J Med Sci Sports. 2009;19:885-95.

89. Shaw BS. Resting cardiovascular function improvements in adult men following resistance training. Afr J Phys Health Educ Recreat Dance. 2010;16:402-10.

90. Nybo L, Sundstrup E, Jakobsen MD, Mohr M, Hornstrup T, Simonsen L, et al. High-intensity training versus traditional exercise interventions for promoting health. Med Sci Sports Exerc. 2010;42:1951-8.

91. Dolezal BA, Potteiger JA. Concurrent resistance and endurance training influence basal metabolic rate in nondieting individuals. J Appl Physiol. 1998;85:695-700.

92. Leveritt M, Abernethy PJ, Barry B, Logan PA. Concurrent strength and endurance training: the influence of dependent variable selection. J Strength Cond Res. 2003;17:503-8.

93. Keese F, Farinatti PV, Pescatello LS, Monteiro W. A comparison of the immediate effects of resistance, aerobic, and concurrent exercise on postexercise hypotension. J Strength Cond Res. 2011;25:1429-36.

94. Hayashino Y, Jackson JL, Fukumori N, Nakamura F, Fukuhara S. Effects of supervised exercise on lipid profiles and blood pressure control in people with type 2 diabetes mellitus: a meta-analysis of randomized controlled trials. Diabetes Res Clin Pract. 2012;98: 349-60.

95. Borg GA. Perceived exertion. Exerc Sport Sci Rev. 1974;2:13153.

96. Borg G, Ljunggren G, Ceci R. The increase of perceived exertion, aches and pain in the legs, heart rate and blood lactate during exercise on a bicycle ergometer. Eur J Appl Physiol Occup Physiol. 1985;54:343-9.

97. US Preventive Services Task Force Procedure Manual. 2008. http://www.uspreventiveservicestaskforce.org/uspstf08/methods/ procmanual.pdf. Accessed September 112014.

98. National Institutes of Health. Clinical guidelines on the identification, evaluation, and treatment of overweight and obesity in adults: The evidence report. Obes Res. 1998;6 Suppl 2:51S-209S.

99. Writing ESC guidelines: Recommendations for guidelines production. 2014. http://www.escardio.org/guidelines-surveys/escguidelines/about/Pages/rules-writing.aspx. Accessed September 112014.

100. McAlister FA. The Canadian hypertension education program: a unique Canadian initiative. Can J Cardiol. 2006;22:559-64. 